\title{
Painting with Metal Spray
}

\section{How Protective Coatings Are Shot Into Place Under the Latest Procedure}

By Robert G. Skerrett

$\square$ LECTROPLATING and galvanizing C are well-proved and widely applied processes that have many fields of usefulness. Indeed, they would be resorted to far more extensively if there were not conditions that make this prohibitive. That is to say, many metal articles might be plated to advantage if their basic substances could resist the while the corrosive attack of the electrolyte employed; and the size and structural get-up of other metallic bodies are such that it is commercially impracticable to provide a zinc bath large enough to admit of their treatment.

Nevertheless, metal coatings have been devised that are handled more or less like paints, and to a point these have served fairly well although admittedly not as durable or satisfactory as the shielding film 'deposited electrically or by dipping in a bath of molten metal. The fundamental weakness of these painted-on or stuck-on coatings has been the lack of intimate union between the underlying and the attached metals. However, years of scientific research and inmetals. However, years of scientific research an mercial stage a flexible system which makes it possible to form a covering film by spraying melted metal upon a variety of surfaces for protective or decorative purposes. In this the achievements of M. U. Schoop, or Zürich, Switzerland, are conspicuous.

The Scientific American has previously described the Schoop process - the last article appearing a little over six years ago. Since then this ingenious engineer has pushed steadily onward, improving. the while earlier apparatus and creatin still newer instrumentalities that add greatly to the capabilities of his spraying method. For a time Schoop relied upon an oxy-hydrogen flame either to melt powdered metal or to fuse a wire which, while in the molten state, was atomizerl by a stream of compressed air and driven at considerable velocity against the surface to be coated. Now, he employs an oxy-acetylene jet, and this has proved quite 50 per cent superior. The higher temperatures obtained in this way insure better results, give the metal coating pistol a longer effective range, and make it feasible to handle efficiently metals differing widely in their melting points.

A few years back the somewhat delicate mechanism that fed the wire into the flame of the blowpipe wa operated by a small pneumatic turbine which made about 28,000 revolutions a minute. This meant that a rather complex reduction gear was required in order to transmit a far more sluggish movement to the fusing wire. The commercial demand was for a pisto of really rugged construction which could be entrusted to the average workman and his commonly unskilled manipulation. To this end, a pistol has been produced which is equipped with an air-driven Pelton wheel which makes between 4000 and 5000 turns a minute. The wire-feeding feature is, in consequence, now reasonably robust, and the speed adjustment of the feed is simplified to a marked extent.

But probably the greatest step forward has been in the substitution of the electric arc for the gas flame. In the "Electro-pistol," which functions with either direct or alternating current, two wires, moving toward each other, form part of moving toward each other, form part of the circuit. The two free or open ends of this circuit are brought together and then separated just far enough to induce an arc; and this distance is maintained as the wires are uniformly fed into this arc and fused. At the same time. the melting terminals are swept by a jet of compressed air, and this atomizes the

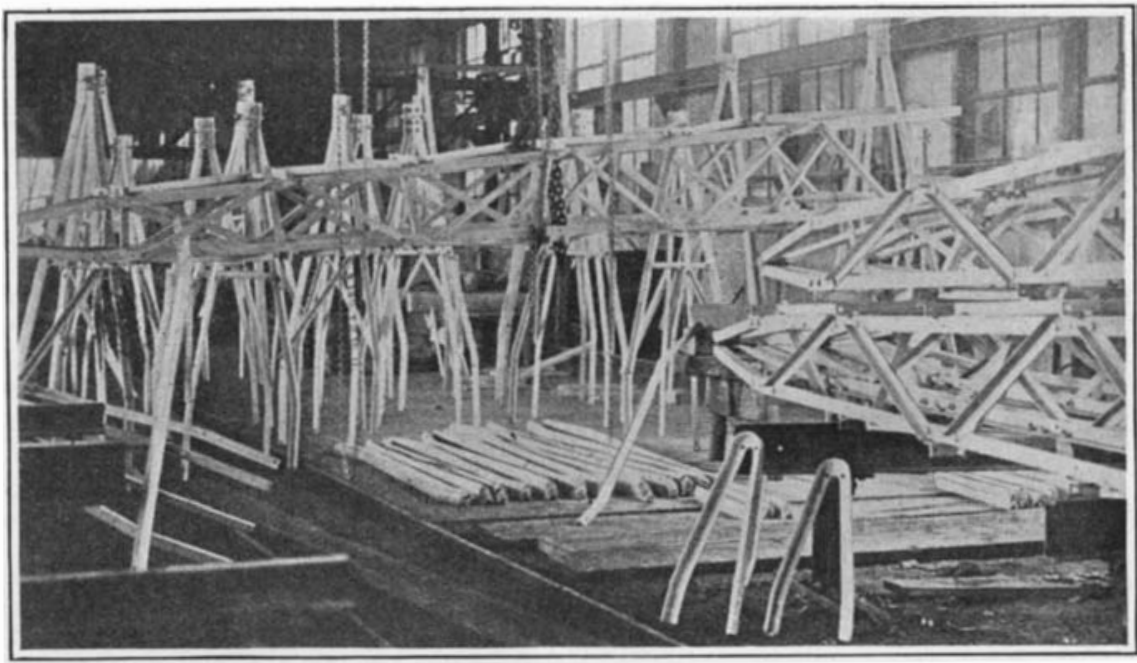

and spreaders for the Swiss electrified railways, which were galvanized by the spray system

metal and drives the plastic globules against the surface to be coated. The temperature of the arc is higher than 5400 degrees Fahrenheit and, therefore sufficient to permit the melting and spraying of plati-

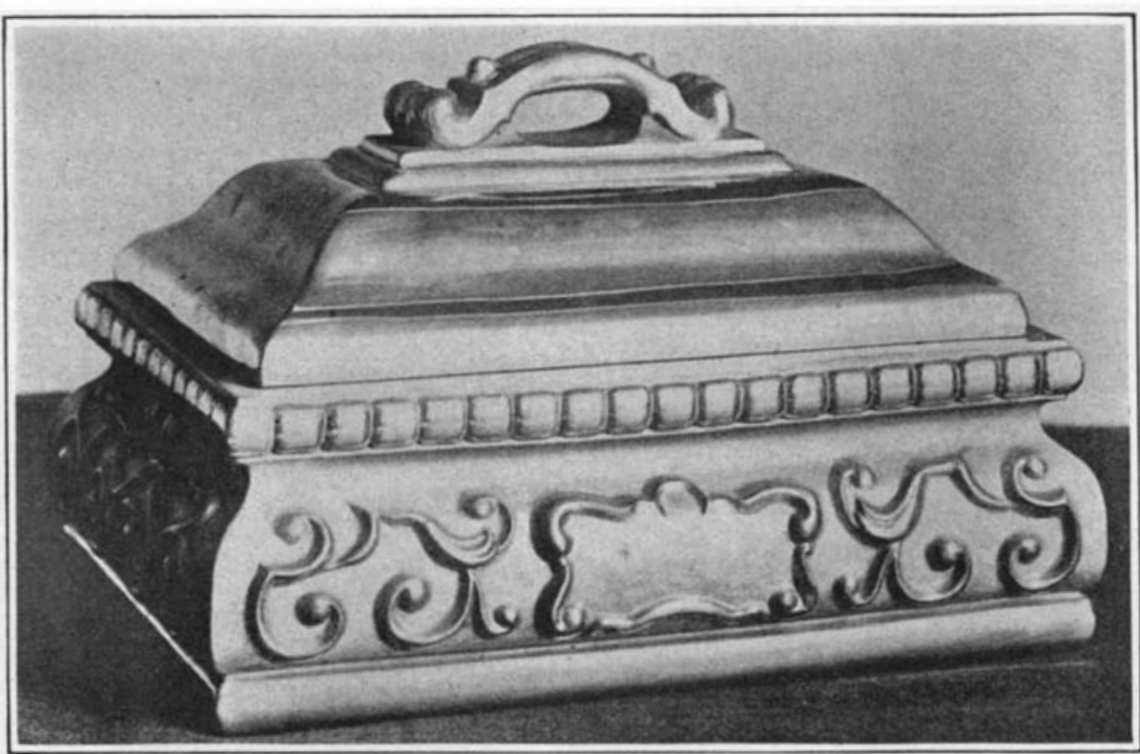

A terra-cotta box that has been bronzed by the spray method

num, molybdenum and other very refractory metals. The electro-pistol weighs only 3.3 pounds. uses 40 amperes of current at from 25 to 30 rolts. and calls for an expenditure of 17.6 cubic feet of compressed air

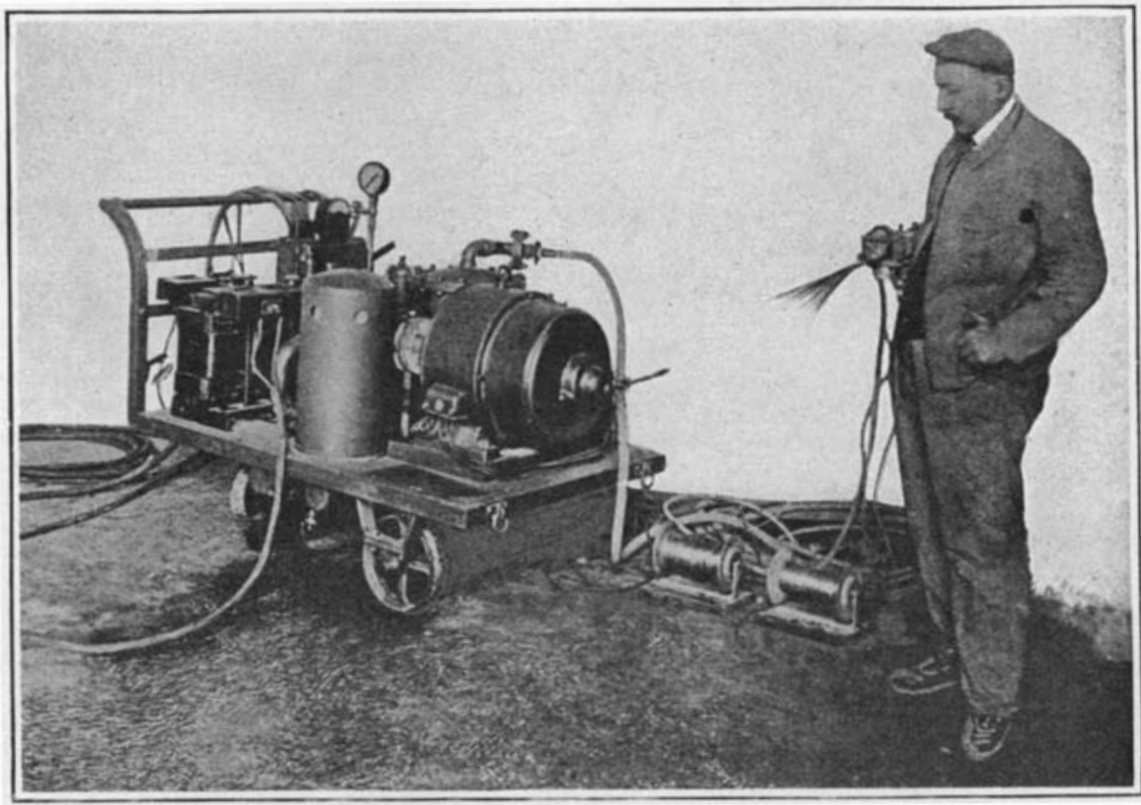

A portable plant for the operation of the "electro-pistol," making it possible to deal with structures heretofore inaccessible per minute, which is supplied at a pressure of 3 atmospheres. In this connection it is interesting to note that School has found, in the course of his developmental work, that it is not essential to employ an air impulse of very high pressure to get a spray fine enough for his purpose and to propel the metal particles a suitable distance from the pistol to the object to be treated. Originally he experimented with pressures ranging from 35 to 40 atmospheres, and these he stepper down to 12 atmospheres with which he practised for some time. Later on with proper facilities, air at 6 and 7 atmospheres answered. At present there are in service many hundreds of his various types of metal-spraying pistols that are operating satisfactorily with an air impulse of $2 \frac{1}{2}$ or 3 atmospheres.

Ten years ago the efficiency of the Schoop-spraying apparatus was comparatively low, for then, of the total volume of metal heated and sprayed, only 30 per cent was deposited, the remaining 70 per cent being dissipated in the atmosphere and in a way to interfere with the breathing of the operative. The pistols now use are able to deposit 90 per cent of the metal atomized; and in the case of aluminum the factor of efficiency is 95 per cent. In the past only tin, lead, and zinc could be handled, but the list of metals that can now be precipitated by the process is a far longer one-in fact, it includes any that can be fused by either the oxyacetylene flame or the electric arc.

In 1912 Schoop demonstrated that it was feasible to melt, to diffuse, and to deposit enamel, glass, quartz, etc., on suitable hodies, but he elected at that time to devote all of his energies to the problems relating to metal spraying. Within the past year, however, he has again taken up enameling, and his accomplishments open up new avenues of application for his broad system. Even when silicate of lead is added to reduce the melting point of enamel or glass, still temperatures running from 1112 degrees to 1292 degrees Fahrenheit are necessary, and it is therefore practicable to coat only materials that can withstand exposure to that heat without injury. The surfacing substance may be in a powdered or granular state or it mav be in some other form which is not so readily fused. Care has to be taken to see to it that the driving medium, compressed air or inflammable gas, shall be so controlled that it will not exert a troublesome cooling effect before the vitreous material has reached the object to be covered. It seems that by the admixture of coloring matter it is possible to give the enamel or glaze any desired tint; and there is reason to believe that this new evolution of the process can be used to advantage both in the field of art and in many departments of industry. The glaze or enamel imparts a brilliant and keautiful finish, according to the composition. Not only that, but the coatings are of a pronounced refractory character. Indeed, tests have repeatedly revealed that tin and other metals so enameled can be heated to rednes in a Bunsen flame and then plunged $\mathrm{di}$ rectly into cold water without causing the film to peel off or crack.

As the Schoop system stands at present, the spraying pistols are of three types: and, whether the heating agency be oxy acetylene gas or electricity, they render it feasible to deal with powdered metal or wire or vitreous substances. Each pat tern of pistol has its virtues, and, there fore, is able to meet special requirements or conditions. These several apparatus may be operated from stationary or portable plants. The portable equipments are (Continued on page 13\%) 
Painting with Metal Spray (Continued from page 128) particularly serviceable when outdoor structures, large castings, etc., have to be treated where they are located for the nonce or permanently. The Schoop interests have devised a "Metallisator" of moderate dimensions which permits the rapid galvanizing, tinning, leading, etc., of quantities of small metal articles. The latter are rotated in a tumbling barrel or drum, and attached to the support. ing shaft is a spraying pistol which oscillates so that it will scatter the molten metal in every direction. By the aid of this machine numerous products can be handled quickly and cheaply. In zinc coating by this means the protective metal penetrates into the pores and interstices of the supporting mass and produces a uniform film which is so nearly permanent that it will give without breaking to hammer blows and repeated bending stresses.

The Schoop process has been employed beneficially in leading the iron buckets of Pelton wheels in hydroelectric plants abroad. Ordinarily, these buckets, when exposed to on-coming sand and gravel, are rather rapidly worn away. The lead coating arrests this destructive action, for the impacting abrasives actually tend to anchor the lead more securely to the underlying iron, while the grit or gravel exerts but a very moderate erosive effect upon the protecting film. Chemical vessels of iron have been made resistant to corrosion by surfacing them, according to the nature of the chemicals to be handled, with lead or aluminum. This expedient has insured longer life and brought about substantial economies.

As might be expected the main use of the metal-spraying process is for zincing. This system has gained extensive recognition in Switzerland, France, Italy, and Germany. Two years ago the Swiss Government adopted the Schoop method of galvanizing for the state railways and now employs it widely in the iron and steel shops and in the locomotive and car works at Neuhausen and Schlieren. The transmission towers and spreaders of the St. Gotthard electrified line, two railway hridges, and the underbodies of 20,000 cars have been zinc coated in this way Rain falling upon laden coke and coal carriers absorbs some of the sulfur content of the fuels, and this water promotes deterioration of any iron or steel it may reach. A zinc film is much superior to paint and more lasting as a safeguar against this harmful action. The Swiss have also found it desirable to supplement the zinc coating of their bridge with one of sprayed lead wherever the steel or iron fabric lies in the sweep of gases from locomotive smokestacks.

According to the latest reports, the electro-pistol is said to be superior to the gas pistol both in a technical and in an industrial sense. The zinc coating ranges in thickness from .003 to .005 millime ters and a capable operative can galvanize a square meter of surface in the course of from 6 to 7 minutes. The potentialitie of the process in the electro-technical and electro-chemical fields are too numerous to mention. A single example, however will serre as a hint. It has been established that a substantial gain can be made in the direction of increased efficiency and greater operative safety by partly coating high-tension porcelain insulators with a film of copper deposited by spraying. The municipal electric plant of Stockholm has placed in one transmission line as many as 25.000 of these metal-coated insulators; and a porcelain factory at Hermsdorf is using a battery of Schoop pistols right along in the manufacture of insulators. The copper coating gives excellent contact surfaces, and owing thereto transmission sistances are reduced proportionately.

Theoretical objection to the Schoop system has been advanced by some critics on (Continued on page 139)

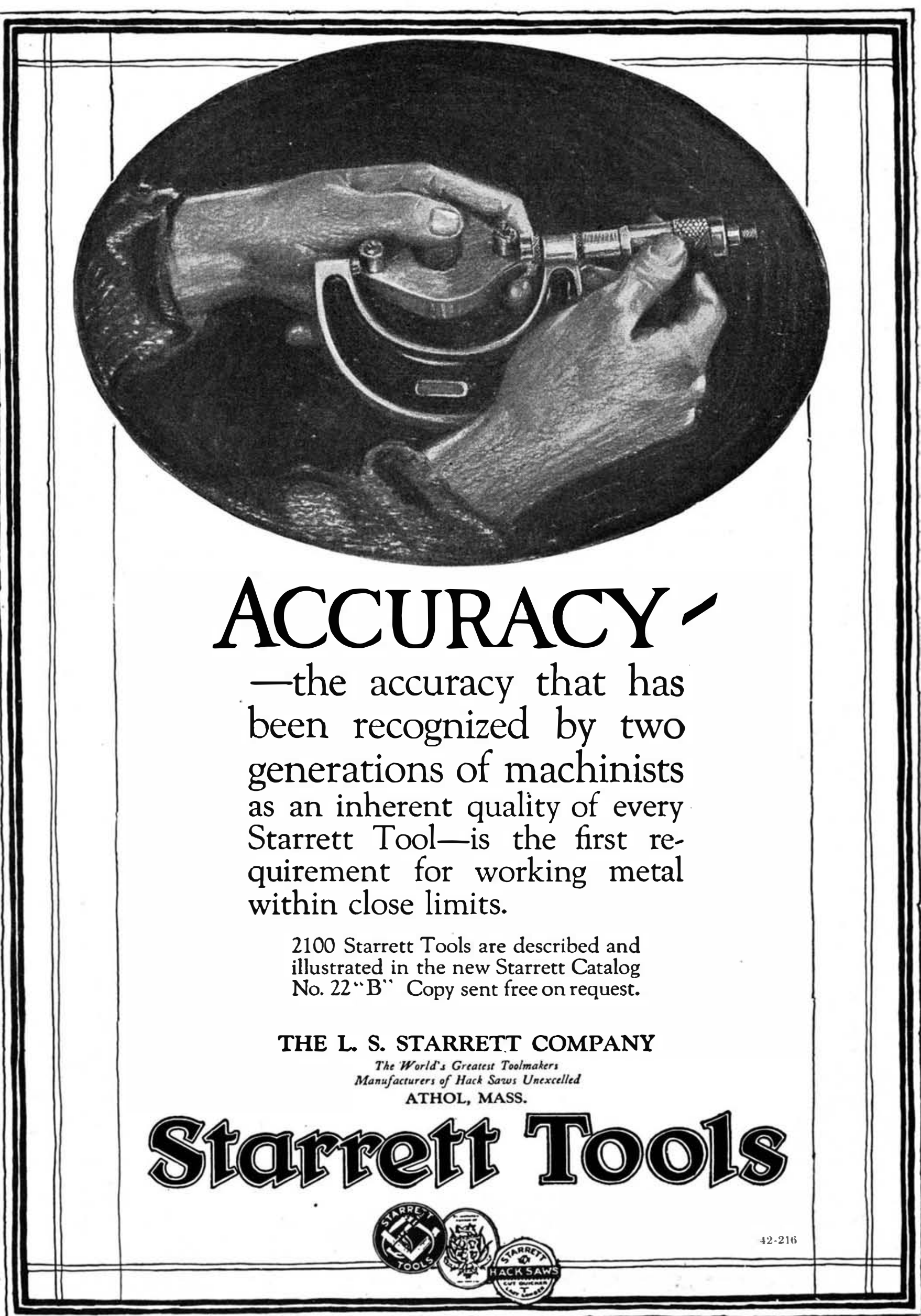

Starrett Combination Squares Graduated with Metric Measure Now Available

Machinists and carpenters working in metric measure will be interested to know that Starrett Combination Squares are now available with the millimeters. These squares are similar in all other respects to the well-known line of Starrett
Combination Squares No. 23, listed on page 62 Combination Squares No. 23, listed on page 62
of the new Starrett Catalog No. 22. The metric scuares are listed as No. $23 \mathrm{M}$ and are made in three sizes determined by the length of blade, and $30 \mathrm{~cm}$. All sizes are sent equipped with Starrett Center Head, in addition to the regular frame, unless otherwise ordered. When ordered
without center head, a suitable reduction in

price is made. Prices of all sizes with and with-
out center head are given in Starrett Catalog, Improved Universal Bevel Protractor Added to Starrett Line To all users of protractors, the Starrett line of these instruments has long been favorably known for their wide utility, accuracy, and con tractor No. 359, recently added to the Starrett line and listed among the new Starrett tools in the latest Starrett Catalog No. 22, this utility and convenience has been still further developed. Instead of the disc being graduated in degrees from 0 to 90 each way, the new protractor has $\begin{aligned} & \text { frame, unless otherwise ordered. When ordered } \\ & \text { without center head, a suitable reduction in }\end{aligned} \begin{aligned} & \text { a dial graduated to degrees throughout the } \\ & \text { entire circle. Encased in the body of the in- }\end{aligned} \mid \begin{aligned} & \text { may also be had without the acute angle } \\ & \text { ment, at a suitable reduction in price. }\end{aligned}$

strument is a new positive method of making so arranged as to permit of control from the center of the front side of the tool, a feature largely contributing to the superior convenience of this protractor in service. This arrangement consists of three nuts centering upon each other path the middle nut at a slight downward prossure engaging the fine adjusting device, while the upper nut locks the blade at any point in its length. An acute angle attachment is also furnished by means of which small angles can

Starrett Universal Bevel Protractors may be with or without leather cases. The protracto may also be had without the acute angle attach- 


\section{Painting with Metal Spray} (Continued from page 137)

the ground that oxidation would prevent the formation of a homogeneous layer of protecting metal. Practical results contradict this assumption. It is true that in most metallurgical processes gas and air do affect melted metal and frequently l)ring about rapid oxidation; and on the face of it one might imagine that the same phenomena would occur with atomized, molten metals. But the speed with which fusing, projection, and "freezing" of the atomized metal takes place, in relation to the comparatively moderate temperature employed, is greater than the rate at which reaction would have to occur to induce oxidation. In other words, it is feasible to melt and to solidify a metal so quickly that there is not time enough for the absorption of oxygen or other gases. In proof of this, Schoop has fused lead and then sprayed it with a stream of compressed oxygen, obtaining thereby a normal, homogeneous layer of the metal without any trace of layer of the

In Germany wooden tobacco pipes and the inner surfaces of beer kegs have been "metallized' to protect them against fire in one case and to make them tight and more durable in the other. Telegraph and telephone poles have had their buried ends and a section immediately above the ground sheathed with a film of lead to prevent rotting; and the blades of aircraft propellers have been coated with aluminum. Metal-spraying pistols are being used to surface with aluminum or copper aprons, smocks, gloves, etc., worn by workers in chemical factories and laboratories where the fabrics might otherwise absorb chemicals and become dangerously combustible if brought close to a flame. The point to be noted is that materials which are normally considered materials which are normally considered more or less inflammable can be covered
with a skin of metal without being inwith a skin of metal without being inother works of art can be gilded, silvered, coppered, bronzed, etc., by means of the Schoop apparatus. The work is of such a character and the texture so true to the nature of the metal that the eye is readily deceived as to the identity of the underdeceived as to the identity
lying supporting substance.

Housework in the Laboratory (Continued from page 130 )

tween sewing and sweeping and washing. Washing at the tables of varying elevations exacted different ratios of heat out put: Twenty-one calories were required put: Twenty-one calories were required ble position, 25 calories when the pan was so stationed as to necessitate raising of the arms, and 30 calories when dishwashing was reduced to a back-bending job. The unpleasantness of the task was not broached by the experimental conclusions.

Laundry operations, both washing and ironing, were not outside the province of these observations. The work was done on towels 16 inches square. The washing equipment comprised a small galvanized iron tub and a scrubbing board, while the ironing was accomplished with a 5-pound iron on a table of suitable height. A towel was rubbed on the scrubbing board 40 times in 30 seconds, wrung by hand for 15 seconds, and then exchanged for an other towel, 15 seconds being allowed for transferring. The energy output in washing was 49.6 calories per hour, thu earning for the assignment the classification of laborious toil. The presence of water in conducting the experiments would undoubtedly have increased the figures of heat requirement, as it would have enhanced the weight of the towe as well as wet articles would have offered more resistance on the scrubbing board and in wringing. Ironing proceeded at a rate of 70 strokes in 50 seconds, $10 \mathrm{sec}$ onds being allowed for exchanging towels A cold iron was used lest heat should obstruct the measurements in the calorime-
ter. The energy expenditure was 24 cal- ories an hour, thus ironing being classified as moderate toil.

The woman subject reposed in a common bentwood chair while knitting, croheting, and hand sewing. Motions, other than those involved in the immediate task, were kept at a minimum. An uncompleted sweater was the object employed in the knitting operations, 23 stitches being administered to the minute. A simple pattern and fine cotton thread were used in the crocheting experiments. Hand sewing included varying types of work: stitch) on the edge of a small piece of fine linen, at the rate of 18 . stitches a minute; simple running on light cotton goods, 6 stitches being taken on the needle, one to one beat of the time-measuring instrument, then the thread pulled through to four beats, with a total of 30 stitches per minute; hemming on light cotton goods, at a rate of 30 stitches to the minute, the thread being pulled all the way through after each stitch; darning light-weight cotton hose with a threa about 24 inches long. Such tasks entail a relatively small expenditure of energy, ranging from 7 calories an hour for sewing with the running stitch to 10 calories per hour in hemming. The heat output while knitting, 10 to 11 calories an hour, slightly exceeded that entailed in crocheting, 8 to 9 calories. The variation is attributed to the wool sweater being knitted weighing more than the cotton lace which was crocheted. Also a more liberal play of hand and arms was involved in knitting. The materials in hand sewing being approximately of the same weight the differences in heat expended are attributed to the extent of movement required. With a running stitch, 7 calories per hour, the movement of drawing the thread to its full length was made only every six stitches or five times a minute, whereas with hemming, 10 to 11 calories an hour, it was made after each stitch or 30 times a minute Needleworkers, in practical operations, avoid the long thread because of undue exercising of the arms.

Advocates of modern conveniences in the home, it would seem, can draw an effective object lesson from these experimental conclusions which accurately determine energy expenditure in the performance of household tasks. Even under the most pleasing environments the housewife spends liberally of her reserve forces; when the home is devoid of modern facilities, certainly the toll exacted is not a mere calculation of effort wasted but a sacrificial exaction where human life is abridged.

Simplifying the Coupling of Trains (Continued from page 131)

Where this coupler is used the cars are coupled and uncoupled in the usual manner. The headpieces or mating members of the Futrell coupler are suspended beneath the present draw-bar coupler and are automatically forced and guided toether by means of spring pressure and guide members extending on each side of the opposing head. The Futrell device maintains an airtight joint through its automatic self-locking coupler, and the gaskets meet just before the metal faces of the couplers touch, which allows for
some axial play. This movement blocks some axial play. This movement blocks the escape of steam or air and seals aucape. The coupler's metal pipes, which carry the steam, air and signal system, are hinged to the ends of the other car pipes by means of universal joints. This allows plenty of room or play when the cars take curves or cause movements
which necessitate more or less of the freedom for which the rubber hose make room.

The Futrell coupler connects the steam air, signal, electric light and telephon lines on the trains without men going between the cars or coaches to make the

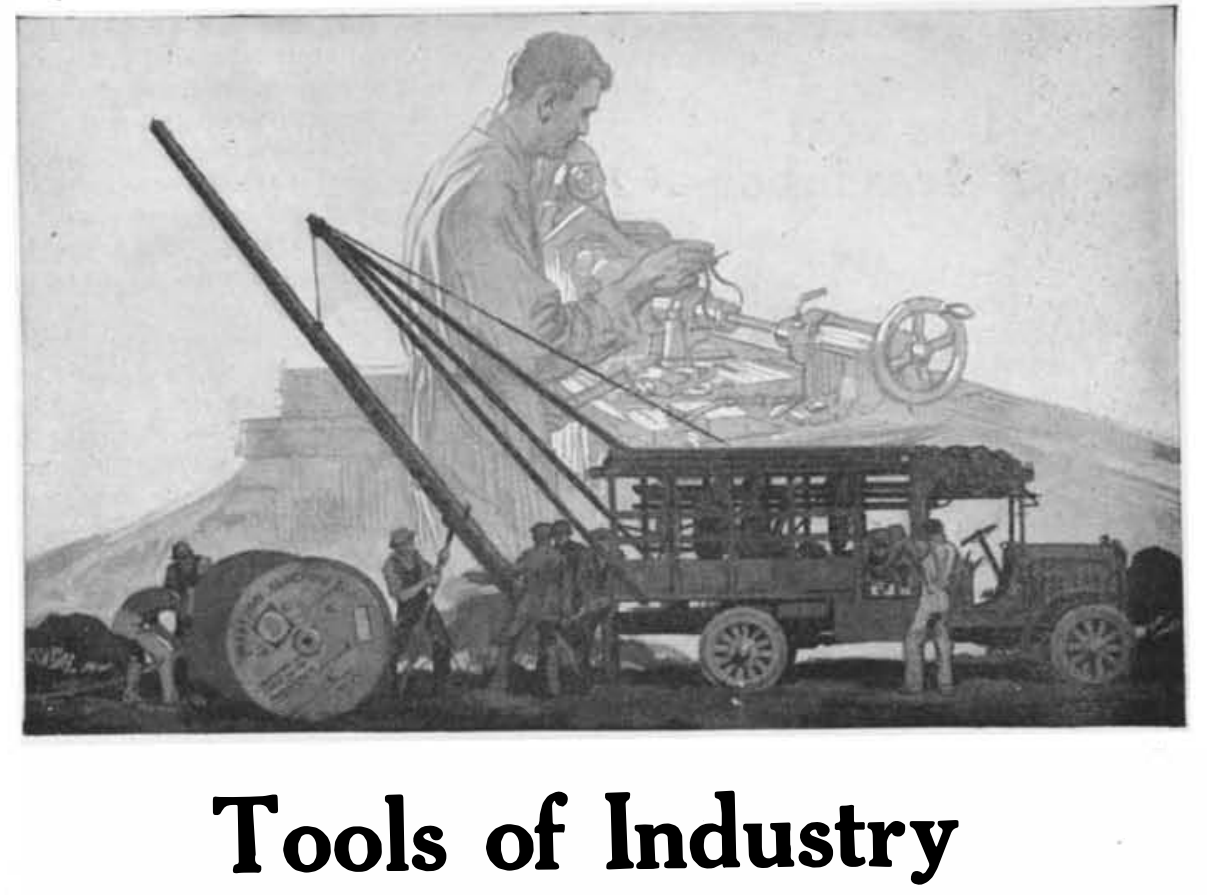

In industry, art, science, in fact in all kinds of work, good results require good implements kept in good condition.

If the right sort of implement is important to an individual workman, efficient tools for industry and commerce are a vital necessity to the nation.

Telephone service is one of the tools of American industry and commerce in most common use and upon which much depends. The American public cannot afford to let this tool get dull.

To provide over twelve million subscribers with telephone connection; to transmit the vibrations of the human voice thirty million times a day and from any point to any other point throughout the land, demands an expensive mechanism of the highest order of scientific precision, and an efficient organization.

It is the aim of the Bell Telephone System, with the cooperation of the public, to be the most dependable tool of American industry.

\section{AMERICAN TELEPHONE AND TELEgRAPH COMPANY
AND ASSOCIATED COMPANIES \\ One Policy, One System, Universal Service, and all directed toward Better Service.}
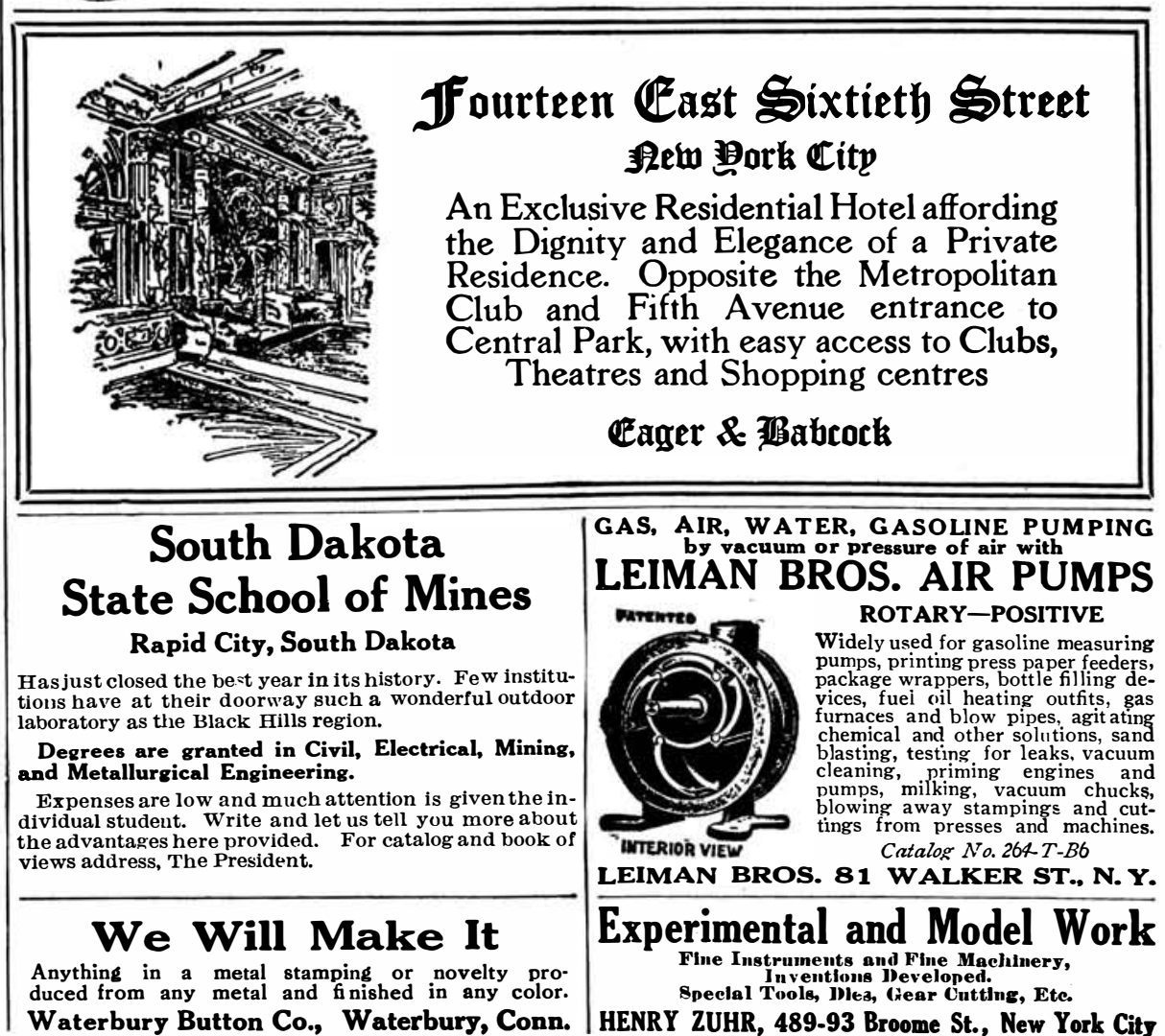